\title{
EL SALÓN DEL TRONO DE CARLOS IV EN EL PALACIO REAL DE MADRID POR FRANCISCO SABATINI
}

\author{
José-Luis SANChO GaSPAR ${ }^{1}$ \\ Patrimonio Nacional \\ RAÚL GÓMEZ EsCRIBANO ${ }^{2}$ \\ Doctor Arquitecto, Universidad Politécnica de Madrid
}

\begin{abstract}
Dentro de la renovación decorativa del Palacio Real de Madrid encargada por Carlos IV a su arquitecto Francisco Sabatini a principios de la década de 1790, la sala más espectacular iba a ser, lógicamente, el Salón del Trono, todo de mármoles españoles y bronce dorado a fuego. El proyecto, iniciado al parecer en 1794 pero definitivamente aprobado en 1796, empezó a realizarse, pero se interrumpió en 1798 cuando gran parte del mármol estaba en Madrid y el trabajo en metal iniciado por Giardoni y Leprince. Aunque los diseños originales se han perdido, la minuciosa memoria de Sabatini para el broncista ha permitido elaborar una exacta reconstitución gráfica que rescata del olvido lo que hubiera sido el más magnífico interior neoclásico español.
\end{abstract}

Palabras clave: arquitectura de interiores; neoclasicismo; Palacio Real de Madrid; Carlos IV; reconstitución gráfica; Francisco Sabatini; Louis Leprince; José Giardoni.

\section{FRANCESCO SABATINI'S PROJECT FOR THE THRONE ROOM AT THE ROYAL PALACE OF MADRID}

As Charles IV had his Royal Palace in Madrid wholly redecorated in the early 1790 by his court architect Francesco Sabatini, the Throne Room had to become the most splendid of the renovated spaces. Its walls were to be fully covered with Spanish marbles and gilt bronze. The project, apparently conceived in 1794, was finally approved in 1796, and the work began immediately but was interrupted in 1798 when the main pieces of marble were in Madrid yet and the goldsmiths Giardoni and Leprince were on their task. The original plans were lost; however, Sabatini's accurate instructions have made possible a graphic reconstitution which brings back to light what would have been the most magnificent room of the Spanish neo-classicism.

Key words: interior decoration; neoclassicism; Royal Palace of Madrid; Charles IV; reconstitution; Francisco Sabatini; Louis Leprince; José Giardoni.

Cómo citar este artículo / Citation: Sancho Gaspar, José-Luis / Gómez Escribano, Raúl (2020) "El Salón del Trono de Carlos IV en el Palacio Real de Madrid por Francisco Sabatini”. En: Archivo Español de Arte, vol. 93, núm. 372, Madrid, pp. 359-374. https://doi.org/10.3989/aearte.2020.24

La decoración de interiores en los palacios reales españoles del siglo XVIII ofrece un riquísimo campo donde, sin embargo, un cierto aspecto presenta menos desarrollo que en Francia o Inglaterra: la articulación de los espacios con elementos arquitectónicos, con órdenes clásicos. La

\footnotetext{
1 jluis.sancho@patrimonionacional.es / ORCID iD: https://orcid.org/0000-0001-8661-668X

2 raulgoes@gmail.com / ORCID iD: https://orcid.org/0000-0002-2968-2901
} 


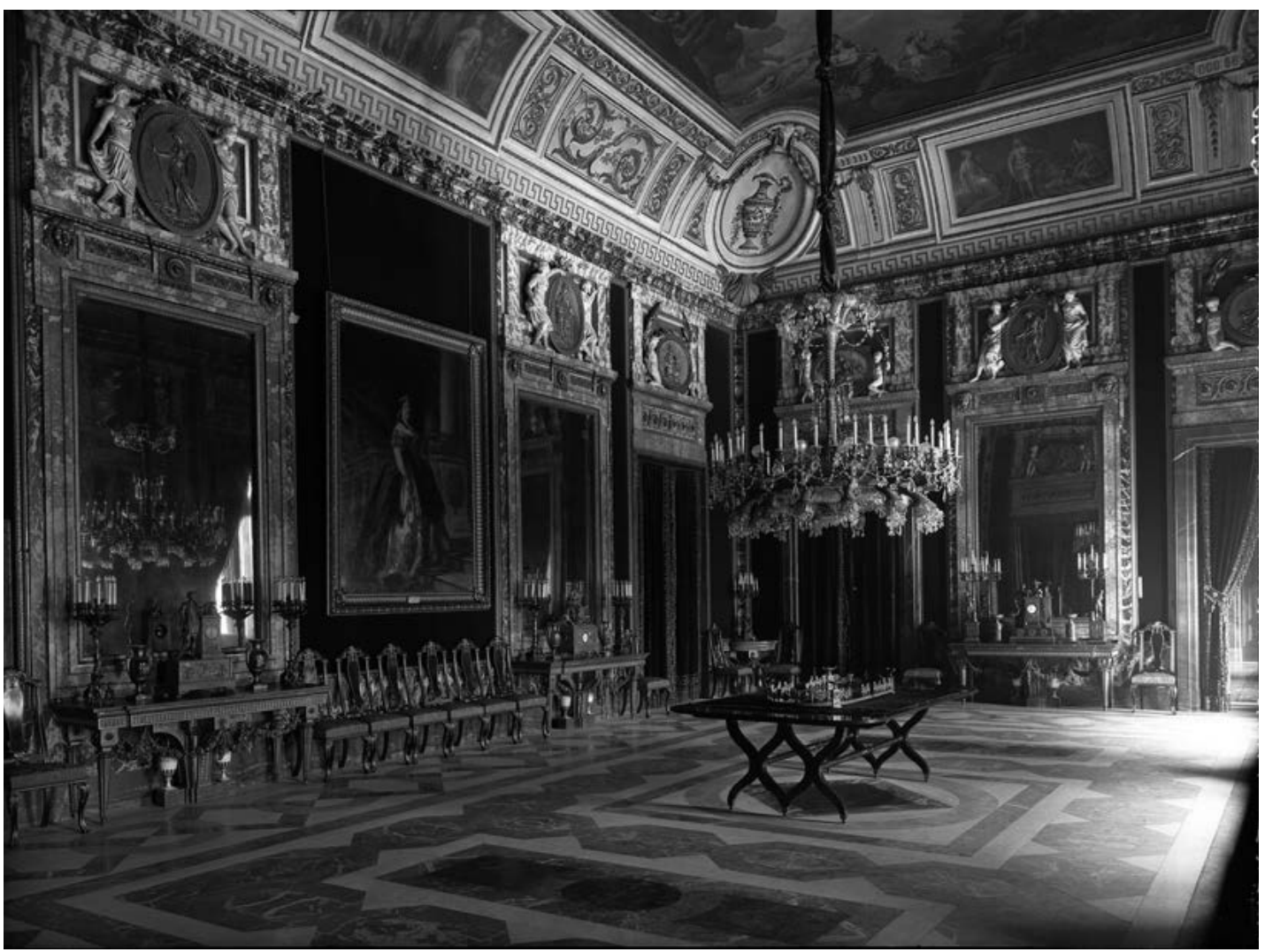

Fig. 1. Salón de María Luisa, o Comedor de diario en el Palacio Real de Madrid. Fotógrafo anónimo, 1931-1945 c. AGP, Fotografía histórica, inv. nº 10180811. (c) Patrimonio Nacional.

galería de Juvarra en San Ildefonso o los proyectos de Sacchetti para los salones del Palacio Real de Madrid abordan este campo del que Carlos III, sin embargo, se apartó para atenerse preferentemente al ornato textil, tan propio de la tradición hispana. Carlos IV, aficionado a crear interiores preciosistas de manera compulsiva, encarga algunos con órdenes clásicos, sobre todo en la Casa del Labrador, pero la propia escala de sus casas de campo hace que tales espacios carezcan de la ambición representativa propia de una gran residencia regia; incluso Percier y Fontaine lamentarían, años después, que les hubiese encargado el Gabinete de platino para un edificio cuya irrelevancia estructural lo condenaba a una previsible desaparición, en lugar de haberles pedido algo grande para el Palacio Real de Madrid, edificio que apreciaron debidamente ${ }^{3}$.

Sin embargo, Carlos IV encargó magníficas decoraciones fijas para el Palacio de Madrid a su arquitecto Francisco Sabatini: los salones ahora llamados "de espejos" y "comedor de diario" forman parte de una campaña decorativa unitaria de renovación ${ }^{4}$, y manifiestan con una voluntad evidente de ofrecer una imagen rica y de nuevo gusto, aunque más italiano que francés, como si fuese más apropiado para la solemnidad monárquica ${ }^{5}$ [figs. 1 y 2 ]. Esas salas son bien conocidas

3 Sobre los salones de Sacchetti, Sancho, 1988. Sobre la Casa del Labrador, Jordán de Urríes 2009. La reconstitución gráfica que aquí se presenta ha sido realizada por Raúl Gómez Escribano. Agradecemos el apoyo prestado por Victor Cageao y Luis Pérez de Prada en la Dirección de Inmuebles y Medio natural del Patrimonio Nacional, para la cual desarrolla José Luis Sancho sus trabajos de investigación, del que este es parte. Así mismo, a Noe Varas Teleña por sus observaciones al texto.

4 Junquera, 1979. Sancho, 1993: 143-165 y 236.

5 Sancho, 2009: 38-43. Para uno de los dos salones de besamanos de la reina, el actual "comedor de diario", proyectó Dugourc una decoración, también de orden corintio, sobre cuyas concomitancias y relación cronológica con el 


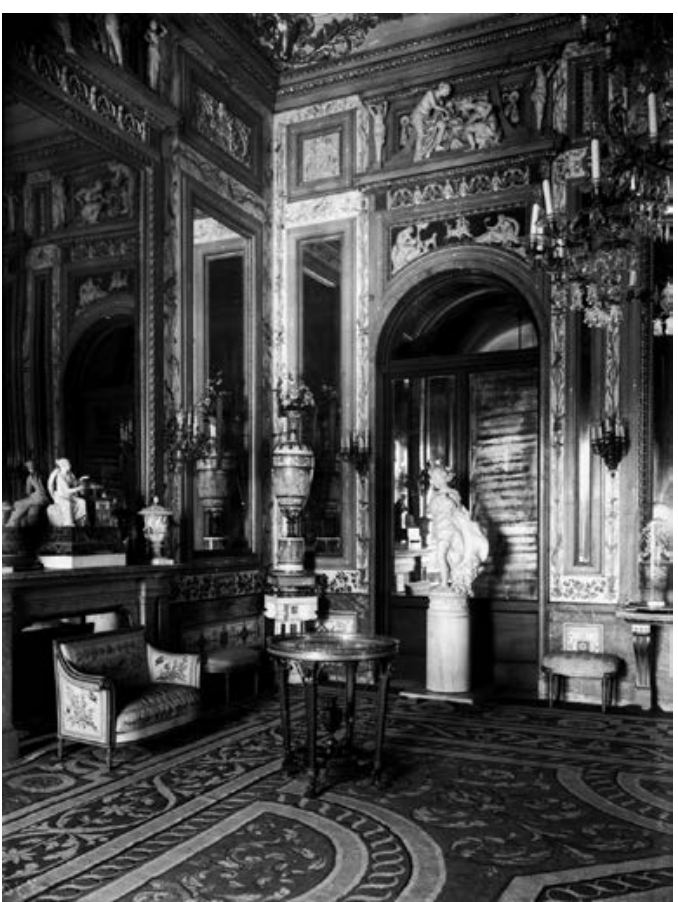

Fig. 2. Tocador de María Luisa, o Salón de Espejos, en el Palacio Real de Madrid. Fotógrafo anónimo, 1940-1950 c. AGP, Fotografía histórica, inv. nº 10152345. (c) Patrimonio Nacional.

y, sin embargo, la que iba a ser más rica entre ellas ha pasado prácticamente desapercibida hasta ahora: lógicamente, se trataba del Salón del Trono, o de besamanos del rey. No se trató de un mero proyecto, sino que su ejecución se inició, quedando truncado en mitad de su proceso ${ }^{6}$. Su conocimiento arroja una nueva luz sobre la importancia que a su imagen pública daba Carlos IV, soberano cuyo activo interés por las artes constituía una de sus facetas más vivaces, nada subordinada a su valido Manuel Godoy, con cuya temporal salida del favor regio en 1798 no creemos tenga nada que ver el abandono de esta obra, debido a las dificultades de toda índole surgidas durante el proceso de ejecución. En ningún momento se planteó sustituir el fresco de Giambattista Tiepolo, tan admirado por los viajeros contemporáneos, aunque como veremos sí se sacrificaban sus dos sobrepuertas.

No conocemos un documento que exponga el plan de conjunto que Sabatini hubo de llevar a cabo para Carlos IV en el Palacio Real durante la década de 1790 y hasta su muerte en 1797, pero resulta evidente que los esfuerzos decorativos se concentraron primero en las habitaciones de la reina y en la Cámara del rey, con los respectivos oratorios de los soberanos, entre 1790 y 1794. Solo a partir de este año pudo comenzar Sabatini a concentrarse en lo que sin duda estimaba iba a constituir su obra maestra dentro de los palacios reales españoles, sacándose así la espina de que en 1760 el conde Felice Gazzola, como asesor artístico de Carlos III, encomendase los diseños para el Trono a Giambattista Natali.

\section{Dibujando Sabatini}

Una de las causas que ha contribuido a olvidar esta importante obra es una circunstancia muy común en el arte cortesano de los Borbones españoles: la pérdida de los planos y dibujos originales. Nada se conserva de ellos; pero gracias a las precisiones y medidas detalladas por Sabatini nos ha resultado posible colmar esta laguna. El proyecto concebido por el "primer arquitecto" hacia 1794 y aprobado definitivamente por el rey en 1796 suponía una completa articulación arquitectónica del "Salón grande del Dosel" con un orden corintio de pilastras y dos columnas flanqueando el trono, todo, en materiales lujosos, con manifiesta voluntad de riqueza material. Aunque no ha aparecido

proyecto de Sabatini trataremos en otro lugar. Su perspectiva a la acuarela, en colección particular francesa, ha sido reproducida por Benito, 2009: 105. Sobre la relación entre los elementos textiles y la arquitectura de Sabatini en ese "Salón de la Reina", ver más abajo, nota 23.

${ }^{6}$ Se había mencionado este proyecto en Sancho, 1993: 236; en Sancho, 2004: 92; y en Sancho, 2017: 24-25, pero no había procedido a publicar la documentación hasta ahora porque era necesario para ello no solo el lenguaje escrito, sino el del dibujo: igualmente gráficos ambos — como con razón suele recordar nuestro común amigo Javier Ortega-, al asociarse la palabra y el diseño no solo acaban por producir una plena comprensión del objeto, sino que durante el proceso interactúan de modo fructífero para llegar a deducciones mejor fundadas. Sobre la importancia histórica, simbólica y artística de este espacio pueden encontrarse las referencias esenciales en dos publicaciones aparecidas simultáneamente, Benito, 2014 y Sancho, 2017. 
hasta el momento la fecha exacta del encargo, este debió de producirse no antes de 1793 y seguramente en 1794, una vez terminados los salones en el cuarto de la reina, porque una serie de trabajos preparatorios que no se improvisan estaba ya realizada en agosto de 1796, cuando el arquitecto exponía al ministro de Hacienda las exigencias económicas de la empresa: "Habiéndose dignado S.M. mandarme executar un modelo para adornar de jaspes de estos Reynos y bronzes dorados a molido el Salón grande del Dosel de este Rl. Palacio, lo hize así, y presenté al Rey, y S.M. se sirvió aprobarlo, en cuya consequencia se están trabajando los jaspes en los talleres de la fábrica del mencionado Rl. Palacio: al mismo tiempo vio tambien S.M. una basa y un capitel de bronce para dicho Salón, y conviniendo se trabaxen a un tiempo los jaspes y los bronces, he formado de estos el adjunto presupuesto del coste a que ascenderá poco más o menos todo lo perteneciente a los adornos de arquitectura" 7 . Puesto que estos modelos, el reconocimiento de las canteras y las maquetas y diseños se elaboraron, según las referencias, a lo largo de 1795, la voluntad regia de realizar este carísimo ornato debió de expresarse el año anterior.

Sabatini hizo realizar una maqueta en la que trabajó el tallista Eustaquio Sancho en el taller del maestro ensamblador de Palacio, Dionisio Aguilar ${ }^{8}$. Según lo que el arquitecto dice literalmente este "modelo" habría quedado terminado, y presentado al rey, antes de agosto de 1796. El memorial de Sancho hace pensar que la elaboración de estas piezas preparatorias se prolongó mientras vivió el arquitecto. También para esa maqueta debían servir algunas piezas realizadas bajo la supervisión de Aguilar por el tornero Juan Manuel de Mora, junto con otras para la Real Botica - que parece correspondían a otro modelo de esa dependencia unas, y para la decoración final otras - y para la Capilla9 ${ }^{9}$ La impresión que ofrece este documento es que Sabatini fue disponiendo la adición al modelo de las piezas torneadas y de talla, encargando su modificación cuando lo consideraba conveniente - su "rebaja" - en virtud del objetivo originario de cualquier maqueta: calcular el efecto producido por las partes ${ }^{10}$.

7 Sabatini al ministro de Hacienda Diego de Gardoqui, 17 de agosto de 1796, adjuntándole el presupuesto o "Cálculo del coste, a que poco más o menos ascenderá la obra de bronces dorados de molido que se ha de hacer a toda costa para el Salón del Rl. Palacio de Madrid, colocada en sus respectivos lugares por lo perteneciente a los adornos de su arquitectura". Archivo General del Palacio Real, Madrid [en adelante AGP], Administración General [en adelante AG], leg. 713. De este mismo documento proceden las citas sucesivas cuando no citamos explícitamente otra procedencia.

8 AGP, Obras de Palacio [en adelante OP], legajo 441, Caja 1341/13. Memorial de "Eustaquio Sancho profesor del arte de tallista y ensamblador", quien "expone daberse empleado por espacio de tres años en el Rl. Taller de VM que está a cargo de D. Dionisio Aguilar durante la obra de la botica Rl., y modelo del Salón de Embajadores en cuyas obras y en otras varias del R1. Servicio se ha portado con toda honradez y exactitud y deseando continuar en el R1. Servicio de V.M. ..." Presentado el 28 de diciembre de 1798, pasado el 3 de enero siguiente a Juan de Villanueva e informado por este el 14 de febrero en sentido positivo ("se ha empleado con inteligencia en el taller de ensambladores en el ramo de la talla, cuando esta ha ocurrido"), aunque no suficiente para cumplir los deseos del interesado, esto sitúa la realización de la maqueta a lo largo de 1795 y principios de 1796.

9 AGP, OP, legajo 441, Caja 1341/13. "Razón de la obra de tornería que yo Juan Manuel de Mora e echo para la Rl. Favrica de Palazio, por orden del Exmo Sr Dn Francisco Savatini, desde el dia 30 de enero del año de 1797. Y es como se sigue:

Primeramente de un Jarrón grande de pino para debajo de la mesa del Salón de Embajadores, 40. Id., de dos colugnas de pino grandes para el modelo del dosel de enbajadores, 40. De cuatro pies de mesa de caoba, 16. De un remate de pino, grande, 12. Id., de revajar por dos veces dicho jarrón del Salón, 24. De ocho florones de caoba, 10. Id., de un molde para un nivel, 16. Id de cuarenta y cuatro borlitas de peral y una corona con su cruz y un zetro y espada, para el dosel del salón, 50. Id., de un florón grande de caoba [...] Id., de añadir una basa a un jarrón para dicho salón, 10. Id., de cuatro piñas de pino, 4

Id., de una piña grande de caoba, para dicho salón, 16. [...] Id., de una piña de pino, 6. Id., de cuatro remates de caoba, 6. [...] Id., de ocho colugnas chicas de peral dóricas y ocho mayores corintias para el modelo de la capilla de S.M., 100. Id., de seis remates de mapa de caoba, 8. Madrid y abril 2 de 1798.

Total, 470." "Se ha de rebajar de esta cuenta 70 rs. vn, y es cierto que ha ejecutado la obra que espresa en ella. Palacio 7 de abril de 1798, Aguilar". Hemos suprimido lo relativo con seguridad a la Botica; también a ella puede que fuesen algunas de las que hemos dejado. El modelo de la capilla suponemos que es para su ampliación en el "Aumento" de Palacio, pero no hay más noticias de esta maqueta.

${ }^{10}$ Como puede advertirse en la cuenta precedente, el jarrón — que estaba destinado a ir debajo del modelo de la consola - primero se presenta, luego se le añade una basa, y luego se rebaja. 
El ornato en bronce "perteneciente a los adornos de su arquitectura", y "todo de bronce cincelado y dorado de molido" está mejor documentado que el de mármoles y, por tanto, es lo que nos ofrece más datos sobre el conjunto. Los muros se articulaban mediante un orden corintio cuyo módulo conocemos gracias a la altura de los "veinte y tres capiteles de pilastras grandes que han de tener de alto dos pies y cinco dedos, y su ancho correspondiente de la orden corintia"11. El entablamento era completo, pues consta que su friso había de estar guarnecido con un festón de laurel "con cintas retorcidas"12; la cornisa, sin embargo, debía de ser toda de mármol.

La presencia de dos "columnas" solas obliga a interpretar que flanqueaban el trono ${ }^{13}$. Ante el número de pilastras surge inmediatamente la sorpresa porque es impar: veintitrés. ¿Cómo se concilia esta evidencia con el obligado reparto de los soportes? Pues en un salón como este todo ha de ser simétrico, y por lo tanto par. La explicación es que Sabatini hace la cuenta sumando los capiteles de pilastra y los de media pilastra; y que había una media pilastra acompañando a cada una de las dos columnas.

Por otra parte, y aunque el arquitecto no diga nada al respecto, esas dos "columnas" solo eran medias, o como mucho de tres cuartos. Lo demuestra la escasa diferencia de precio - solo una sexta parte- entre los capiteles de pilastras y de columnas, que hubiera debido ser mucho mayor si estas hubieran sido exentas. Ambos datos concuerdan bastante bien para definir cómo era el tabernáculo del solio, flanqueado por semicolumnas a las que se adosa por su lado exterior una media pilastra. Esta solución es la misma que Sabatini había aplicado en la Puerta de San Vicente, sin ir más lejos. Francisco Carlier emplea una asociación no muy distinta de semicolumna y media retropilastra en la iglesia de las Salesas Reales.

La indudable existencia de esas dos medias pilastras en el centro del Salón obliga a pensar que Sabatini dispuso también en otros puntos del mismo otras divisiones similares, y concretamente que en los rincones empleó pilastras quebradas en ángulo recto. Tal fórmula es, de hecho una solución habitual, y desde luego la única compatible con el número de soportes ${ }^{14}$. Los fustes plegados en esquina permitían así un despliegue de los espejos que prolongarían visualmente la longitud de esta "galería". Las pilastras enteras, al situarse en el muro del fondo frente a las que flanqueaban los balcones, articulaban los alzados según un ritmo seriado, bien distinto de la homogeneidad que antes $-\mathrm{y}$ hasta nuestros días - domina los paramentos.

En los entrepaños entre las pilastras se disponían espejos y ornatos en bronce y mármol sin duda, pero también quizá en otros materiales ricos. Lo primero que salta a la vista es la disminución radical de los espejos y el cambio en su colocación: su número se reduce de doce a seis. Por tanto, es preciso considerar cómo se situaban: la hipótesis más razonable es que se mantuvieran los dos en cada testero, y que los dos restantes, en el muro del fondo, pasaran a estar frente a los balcones intermedios. De esta manera esa larga pared quedaba ritmada mediante una sucesión de entrepaños "huecos" y macizos, contando entre los primeros las dos puertas de los extremos, los espejos y el solio. Esta distribución de los espejos resultaba más lógica que la anterior, por cuanto así dos de las superficies reflectantes quedaban directamente enfrente de dos balcones. En la decoración de Carlos III eran los muebles los que marcaban los ritmos, y por tanto debían de quedar enfrentados, de modo que a los balcones intermedios respondían tramos de pared sin más adorno que la colgadura. Así pues, el Salón de Sabatini se diferencia del anterior no solo por su articulación arquitectónica, sino porque no son ya protagonistas ni los espejos ni los muebles [fig. 3].

11 Había "veinte y tres capiteles de pilastras grandes que han de tener de alto dos pies y cinco dedos, y su ancho correspondiente de la orden corintia". Esto equivale a $65 \mathrm{~cm}$, exactamente. Existe uno en el despacho del Director de Inmuebles del Patrimonio Nacional, pero tiene solo 45 de alto, así que no puede identificarse con nada correspondiente a este proyecto, aunque sea de la misma época.

${ }^{12}$ El friso de la cornisa tiene doscientos setenta y quatro pies, es decir 76,72 metros. La anchura del festón era de siete dedos, o sea $12,6 \mathrm{~cm}$.

13 "Por otros dos capiteles de columna con sus basas correspondientes de la misma orden, con el propio alto que los anteriores...".

14 Solo así salen 23. Las ocho junto a los balcones obligan a otras seis en el muro del fondo —más el sintagma central con "columnas" - y son imprescindibles dos flanqueando cada puerta axial: en total, 19 pilastras y dos columnas. Por tanto para las esquinas solo quedan cuatro pilastras, una en cada rincón. 

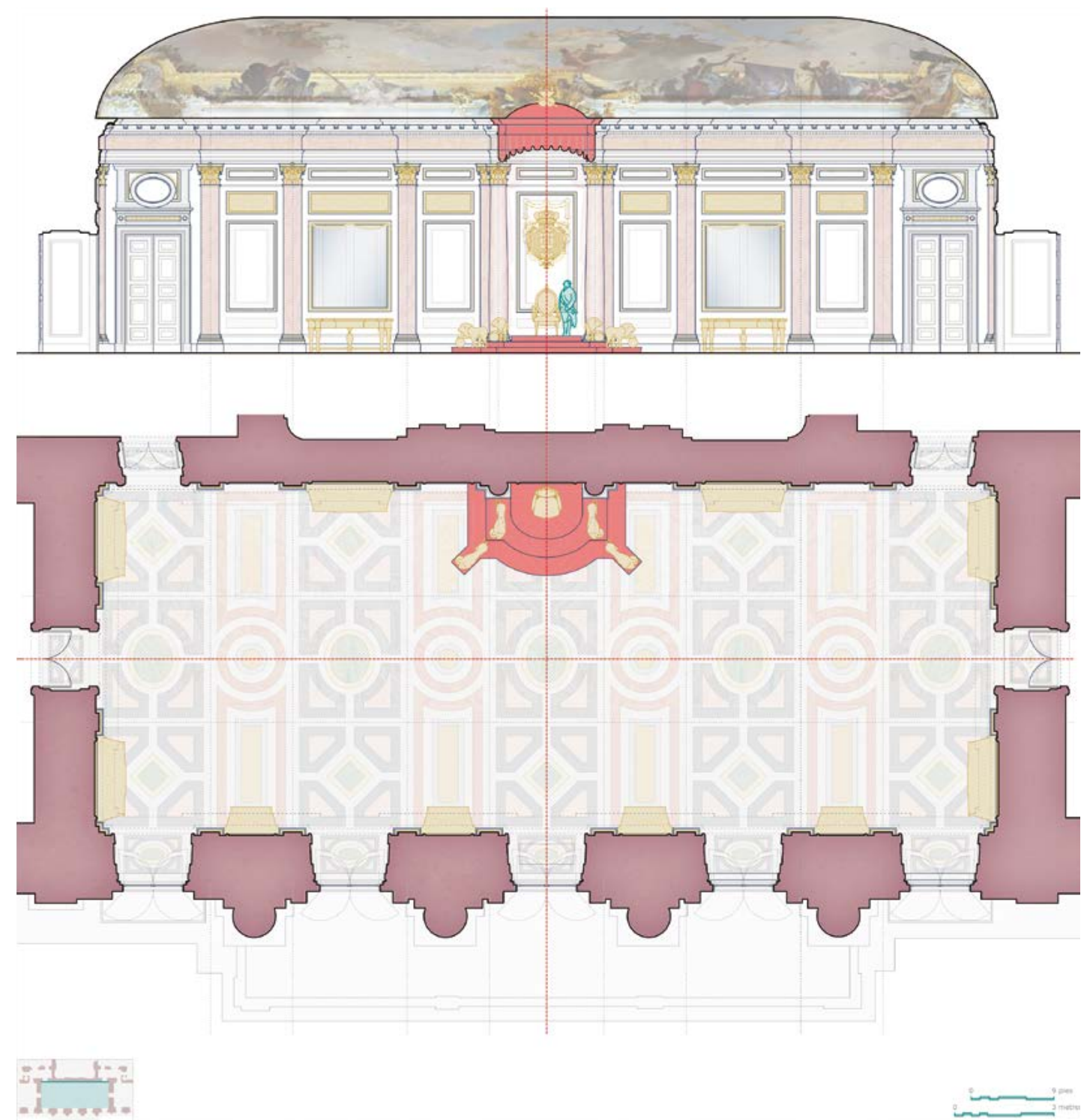

Fig. 3. Reconstitución gráfica del proyecto de Sabatini para el salón del trono. Planta y alzado norte.

Sabatini dispuso diez consolas, de las que seis correspondían a los espejos, y las otras cuatro irían entre los balcones. Andrés del Peral realizó en 1797 un modelo para ellas ${ }^{15}$, sobre el que debían aplicarse los elementos realizados sucesivamente por el tornero Mora.

No solo había menos espejos que los instalados bajo Carlos III, sino que eran bien distintos a los precedentes, pues su perímetro - inferior a los once metros ${ }^{16}$ - los define como más bajos pero más anchos, con lo que ayudarían a producir una ilusión de mayor extensión horizontal del espacio. Iban bordeados con "treinta y ocho pies de moldura de hojas retorcidas al ayre, en su

15 AGP, OP, leg. 195, julio de 1797. Como Peral era dorador y pintor, y en realidad cabeza de una empresa que contrataba amplios trabajos, el autor material del modelo debió de ser un subcontratado suyo. Sabatini acudiría a él como profesional de su confianza y colaborador habitual suyo.

${ }^{16}$ Los seis espejos tenían cada uno treinta y ocho pies de moldura en torno, es decir que su perímetro era de 10,64 metros. Los de Carlos III tienen unos catorce metros de perímetro, según el inventario actual. 
medio pasa un bastón a vaguetado, tiene de ancho esta moldura cinco dedos, y otros tantos pies de fusarolas torneadas con su listón debajo que tapa la junta del cristal, y también tienen dos colgantes de hojas de laurel"17. Las fusarolas - del italiano fusaiola - son el adorno formado por monedas agujereadas y ensartadas en una cuerda, que en el repertorio ornamental francés se denominaba à piastres. La proporción de los espejos, más bajos que los del salón de besamanos de la reina, es inusual y un tanto extraña. Dugourc hizo mucho mejor uso de este recurso en su proyecto para la sala de audiencia de la duquesa de Alba en el palacio de Buenavista, situándolos en alto entre las semicolumnas corintias ${ }^{18}$.

Por lo demás, los muros del salón estaban subdivididos en diversos entrepaños de mármol encuadrados y unificados por una moldura perimetral homogénea "de bronce guarnecido de hojas y fusarolas ..., cincelado y dichas fusarolas torneadas y la referida moldura adornan todos los requadros del citado Salón"19. Sobre cada espejo campeaba un adorno de bronce inserto en un rectángulo: "seis adornos o grecas que van en los seis requadros de encima de los espejos ... a manera de sobrepuerta" ${ }^{20}$. Otros similares adornos había encima de los balcones $^{21}$. Las ocho entrepilastras restantes, donde no había espejos, presentaban "requadros", que armonizaban con los entrepaños ya indicados: también estaban adornados con "ocho adornos o grecas" de bronce cuyas dimensiones ofrecen algunas pistas sobre su proporción ${ }^{22}$. Esta disposición producía una correspondencia muy acompasada, pues como esos "requadros" alternaban con los espejos y todos debían ser de la misma altura, sobre aquellos debía haber otros rectángulos de dimensiones parecidas a los sobre-espejos. Estos rectángulos estaban seguramente reservados a frisos escultóricos, pues así lo indican tanto la comparación con los salones de Sabatini en el cuarto de la reina ${ }^{23}$, como la presencia de bajorrelieves en las dos sobrepuertas nuevas ${ }^{24}$.

Las cuatro puertas presentaban una greca o guirnalda en su "friso" — es decir en la parte superior de su marco-, "con ocho clavos romanos", similar a la que aparece en el gabinete de escayola de la reina ${ }^{25}$. Encima de ellas campeaban cuatro sobrepuertas iguales cuya descripción permite hacerse cargo de su aparatosidad: "Los adornos que van encima de las puertas, la moldura del ovalo del bajorrelieve tiene catorce pies de diámetro y es de piedra: tiene de ancho

${ }^{17}$ El ancho de esta moldura, 5 dedos, equivalía a $9 \mathrm{~cm}$, y los colgantes de hojas de laurel trece pies de largo, o sea $364 \mathrm{~cm}$.

18 Gastinel-Coural, 1990. La expresión "a vaguetado", o sea "abaguetado", se refiere a "baguette", referencia francesa lógica en el contexto de las artes decorativas del XVIII, a través de su versión italiana "bacchetta" o española, "baqueta", "junquillo o moldura redonda".

${ }_{19}$ El perímetro total de esta moldura de bronce era de 1.133 pies, o sea, trescientos siete metros y veinticuatro centímetros, 307,24.

${ }^{20} \mathrm{Y}$ ".... que tienen de largo nueve pies y dos y medio de ancho", es decir $70 \mathrm{~cm}$ de alto por 252 de ancho.

21 "Los otros cinco adornos o grecas que van en los requadros de encima de las ventana", de iguales dimensiones que los precedentes. Los cinco recuadros sobre los balcones no tenían más de $70 \mathrm{~cm}$ de alto por 252 de ancho, porque esas eran también las dimensiones de sus "adornos o grecas" de bronce.

${ }^{22}$ Los ocho principales recuadros entre las pilastras no tenían menos de $154 \mathrm{~cm}$ de alto por 70 de ancho, porque esas eran las dimensiones de sus adornos de bronce, "tienen de largo cinco pies y medio, y dos y medio de ancho".

${ }^{23}$ El Tocador (hoy Salón de espejos), el gabinete de escayola y el hoy llamado comedor de diario, utilizado también para besamanos y con destino al cual realizó Dugourc el proyecto mencionado más arriba, nota 3 . En el efecto general de esta sala, llamada en los inventarios contemporáneos "Salón de baile", o sencillamente "Salón de la Reina", era determinante la colgadura descrita en el inventario de 1813, "de raso liso ancho su fondo color de oro su divujo cenadores y medallas con otros adorno y colgantes de flores con su cenefa de eses adornadas $\mathrm{q}^{\mathrm{e}}$ componen de una fachada original de 3 anchos de raso liso ancho fondo color de oro adornos blancos y azules y de 18 pilastras en los 4 ángulos y medios inmediatos a espejos y bentanas", así como "Una alfombra echa en la fabrica de los tapices con destino para dicha pieza $q^{\mathrm{e}}$ forma un pavimento imitando piedra de varios colores sobre el adornos de color de oro sobre fondo azul sus cenefas exteriores 2 cintas enlazadas amarillas tambien sobre piedra de jaspe". AGP, AG, leg 769.

${ }^{24}$ A propósito de ellas el arquitecto menciona inequívocamente "la junta del bajorrelieve".

25 "Otras cuatro grecas que tienen de largo seis pies y ocho dedos de ancho con ocho clavos romanos de medio pie de diametro, que van en el friso de las sobrepuertas"; dos clavos cada uno, evidentemente. 
cinco dedos toda ha de ser guarnecida de ojas entalladas y otros tantos pies de fusarolas torneadas con su listón debajo de bronce que tapa la junta del bajorrelieve, y los dos colgantes grandes que van alrededor de la moldura de dicho ovalo que tiene de largo 18 pies"26. De entrada, notemos que Sabatini ha eliminado la diferencia entre los dos huecos del eje central y las dos de la pared norte, haciendo las cuatro iguales, cuando en su estado de 1760 solo las primeras contaban con sobrepuertas enfáticas, formadas por un óvalo vertical en grisalla por Giambattista Tiepolo flanqueado por putti de Robert Michel. En una primera lectura la alusión a la forma oval del "bajorrelieve" podría hacer pensar que se trata del monocromo realizado por el pintor veneciano; pero el análisis de sus dimensiones, y de cómo podría encajar con el resto de los elementos descritos y con la cornisa, obliga a concluir que era más pequeño y que solo podía ir en posición horizontal. Por tanto, optó por sacrificar completamente las dos sobrepuertas de la época de Carlos III, y preveía cuatro relieves escultóricos sobre los huecos. No existen más noticias acerca de estas piezas, cuyo encargo es lógico se dejase para una fase más avanzada de los trabajos.

El coste total de todas esas piezas de bronce, sin contar nada más, ascendía a casi dos millones y medio de reales, cifra astronómica en cualquier momento, pero más si se tiene en cuenta la difícil situación bélica con Francia en aquellos años ${ }^{27}$. Sabatini calculó que "Esta obra podrá durar como cinco años" gastando "los mismos cinquenta mil rs., mensuales que se consignaron para los de los oratorios de SS.MM que están ya pagados". El rey, sin embargo, resolvió el 16 de septiembre de 1796 "que se trabaxe poco a poco y que se asignen veinte mil reales mensuales", y esta reducción del ritmo al cuarenta por ciento supone que la obra de bronces se habría prolongado doce años, término que habla tanto de la ambición de la empresa como de su éxito dudoso desde el principio, por excesivamente larga.

De haberse llevado a cabo en efecto se hubiera terminado justamente en la víspera de la invasión napoleónica. Aunque es preciso revisar las cuentas, todo parece indicar que el proyecto se abandonó entre 1798 y 1799, cuando toda la atención del soberano se concentra en la Casa del Labrador y se evade definitivamente del Palacio de Madrid. En este sentido es preciso recordar que el coste del Gabinete de platino, presupuestado inicialmente en setecientos mil reales, llegó casi al millón, y que los gabinetes de bordados en las casitas de Carlos IV también fueron sumamente caros, de tal forma que el suntuoso salón principal del Palacio madrileño quizás hubiera equivalido en total a cuatro o cinco de esos pequeños espacios preciosistas.

Sabatini no solo preveía en la decoración todos esos elementos de bronce en el orden corintio que articulaba las paredes, sino "los bronzes del Dosel, esto es los cuatro leones, la silla, el escudo de armas Rs., y los que llevan las diez mesas" que no estaban incluidos en ese presupuesto, pero cuyo coste calculaba en más de otro medio millón de reales ${ }^{28}$. No deja claro el arquitecto si pretendía sustituir los leones seiscentistas por otros nuevos o solo restaurarlos, pero nos inclinamos a pensar lo segundo. Todos estos detalles han permitido restituir el aspecto que hubiese tenido el salón si se hubiese acabado, como veremos al final.

${ }^{26}$ Esos bronces consisten en un listón "que tapa la junta del bajorrelieve" bajo la moldura que rodea el óvalo. Dicha moldura es de de bronce, de cinco dedos de ancho $(9 \mathrm{~cm})$, y está sobre la de piedra, de 14 pies de diámetro (392 $\mathrm{cm}$ ), que enmarca el óvalo. Habla también de "los dos colgantes grandes que van alrededor de la moldura de dicho ovalo que tiene de largo 18 pies $(505 \mathrm{~cm}$.)". En suma, parece que el marco oval de piedra llevaba por su parte interior una moldura de bronce, que la separaba del bajorrelieve, y por la exterior dos guirnaldas colgantes.

27 Los 23 capiteles de pilastra, a 25.800 reales, 593.400; los dos de columna,61.000, unos y otros con sus basas. Los 1.133 pies de moldura, 781.770; los 274 de festón de laurel en el friso, 178.100; los "ocho adornos o grecas", 96.000; los otros once más grandes, 220.000. las molduras y colgantes de los seis espejos, 249.840; lo de las cuatro sobrepuertas, 101.280, y las grecas en los frisos de estas, 28.000; en total, 2.309.390. rs.

${ }_{28}$ Esto se induce porque sugiere que "se podrán ir satisfaciendo éstos con la misma consignación, aunque dure un año más la obra". 


\section{La ejecución de las obras}

Toda esa obra de bronce fue contratada en 1796 por José Giardoni, por casi dos millones y medio de reales, sin contar las mesas y el dosel ${ }^{29}$. Pero en 1798 este prestigioso italiano fue parcialmente desplazado de este encargo a consecuencia de la solicitud de los doradores franceses Leprince, padre e hijo, quienes habían adquirido favor por parte del rey ${ }^{30}$. Contaban aquí con un apoyo cuya naturaleza exacta no está clara, y que no puede atribuirse solo a la excelencia de su trabajo, pues las obras de Urquiza no dejaban nada que desear como muestran todas las documentadas por Junquera y, sin ir más lejos, las consolas para la sala inmediata a la del Trono ${ }^{31}$.

Ya habían realizado el dorado del capitel y basa que, como muestra, se había presentado al rey en 1796 y, al pedir algo de trabajo en Palacio al nuevo arquitecto mayor, Juan de Villanueva, este consideró que se podía dejar en manos del broncista italiano la ejecución de las piezas, y su dorado en las de los franceses, puesto que "no duda que aquellos [Leprince] lo ejecutarán con más primor" ${ }^{2}$. Resulta extraña esta parcialidad por los doradores galos cuando muchas de las piezas venidas entonces de París volvían a dorarse aquí. El asunto está resuelto el 29 de junio en los siguientes términos: "Que se repartan las obras de que se trata entre Giardoni y los doradores franceses por iguales partes, quedando el aumento de precios sobre el contratado con Giardoni al arbitrio y ciencia de Villanueva, que lo graduará según el mérito de las obras" ${ }^{33}$. Tal resolución manifiesta el interés de Carlos IV por obtener un resultado de la mayor calidad, rayano en el preciosismo al que nos tiene acostumbrados la decoración de sus casas de campo, y en particular la del Labrador; pero pernicioso para la marcha de esta obra pues, al encarecer el costo del dorado, retrasaba el de la ejecución de los bronces, y abría camino a la posibilidad de disputas entre unos artífices y otros. Consta que tanto Giardoni como los franceses llevaron adelante estos

29 AGP, OP leg. 357. Gardoqui a Sabatini aprobando el presupuesto relativo a los bronces de arquitectura que deben ir haciéndose lentamente y pagados por socorros de 20.000 reales. Incluye el borrador de una carta de Sabatini a Gardoqui, de 17.8.1796, sobre el encargo del salón. AGP, OP leg. 357. Presupuesto — dos copias, una corregida en el texto, pero igual en las cantidades - de José Giardoni para los adornos de arquitectura del salón del dosel. Asciende exactamente a 2.309.390 rs. Quizá a esta obra corresponde un Memorial sin fecha en el que Giardoni pedía se le pagasen los modelos que había hecho (leg. 357), pero hemos de tener en cuenta que por entonces también realizaba los bronces para el oratorio del Príncipe y para la chimenea de la pieza del dosel de la reina (leg. 353. 8.8.1794, Oficio de Santa Cruz a Sabatini).

30 Cfr. Martín / Martínez Leiva, 2002.

31 Junquera, 1979: 99. Estas ocho consolas, repartidas entre la Antecámara del rey y el Salón de alabarderos, llevan los $n^{\circ}$ inv. 10007819-22 y 10002593-96.

32 Este juicio se formula en la minuta, y quizá recoge una opinión verbal de Villanueva, pero este, en su informe, solo apunta lo que hemos resaltado en cursiva.

33 AGP, OP, leg. 438. Juan de Villanueva a Francisco de Saavedra, 14 de junio de 1798. "Solicitando los doradores franceses Leprince padre e hijo se les dé algún trabajo por las Obras del nuevo Rl. Palacio, y no existiendo en estas pendientes otro que los adornos de bronce que se van trabajando poco a poco por el broncista D. Jose Giardoni, en virtud de las Rs. Ordenes comunicadas a mi antecesor por el Exmo. sr. D. Diego de Gardoqui con fecha de 10 de septiembre de 1796, deseo saber si será del agrado y voluntad de S.M. que separando la operación del dorado que tenía a su cargo Giardoni, bajo los precios entregados a mi antecesor de materiales, hechuras y dorado, que sirvieron para el cómputo que por aquel entonces se hizo, y manifestó al referido Exmo. Sr. con fecha de 17 de agosto del citado año, importante dos millones trescientos y nueve mil rs., sin contar mesas y dosel, entregue la ejecución de la referida maniobra del dorado a los franceses Leprince padre e hijo, en inteligencia de que éstos me piden y se fijan, por el solo dorado de capiteles y basas, en doce mil rs. por cada juego de estas piezas, habiéndose considerado en el avance en solos nueve mil, los mismos que Giardoni les abonó por las muestras que hicieron y se presentaron a S.M., y en que se ofrecía y ofrece presentemente ejecutar el mismo trabajo, aunque no se asegure totalmente sea con la perfección de los franceses [cursiva nuestra]; y siendo de consideración la diferencia que podrá tener el coste conceptuado, por el exceso de precio en que los Le princes se ha fijado en esta sola parte de obra, y la que podrá resultar en toda la demás ejecutándose por ellos, no me resuelvo a poner en sus manos la obra que se halla hecha por Giardoni en disposición de poderse dorar, sin obtener la debida aprobación de S.M., y órdenes de V.E., en conocimiento de lo que dejo expuesto, y los auxilios y asistencia de caudales que son indispensables para socorrer a los referidos doradores con los que me pidan y sean necesarios en sus trabajos, no siendo suficientes los veinte mil rs. mensuales que por consignación al intento se señalaron en aquel entonces, cuya cobranza no se verifica corriente de algunos meses; sobre todo lo cual espero de V.E. las órdenes que sean de su agrado". 
adornos desde octubre de 1796 hasta diciembre de 1798, repartiéndose el trabajo ${ }^{34}$. Para los Leprince se habilitó una casa propiedad de la Corona en la calle del Barquillo ${ }^{35}$, en 1799 alcanzaron el título de doradores de cámara ${ }^{36}$, y llevaron a cabo otras obras de orfebrería ${ }^{37}$, sin que llegasen a concluir esta, la más ambiciosa y que mayor fama les hubiese reportado; en el entorno cortesano merecieron a veces juicios duros que no ponían en duda su calidad, pero señalaban como excesivas sus pretensiones tanto económicas como profesionales ${ }^{38}$.

No solo la obra de bronce se empezó y avanzó, sino la de los mármoles, no menos magnífica y costosa. Ya desde 1793 consta que se empezó la saca de las pilastras y columnas monolíticas del valle de Luque, en Córdoba, insistiendo siempre en que debían venir sin romperse ${ }^{39}$. Tales advertencias denotan que el arquitecto era consciente de las dificultades que suponía su elección, pues apuntaban ya a los problemas que iban a atrasar y dificultar los trabajos, con gran perjuicio de los contratistas. El principal de ellos era Domingo Álvarez, el padre de quien andando el tiempo sería famoso escultor neoclásico, José Álvarez Cubero. Este, que al año siguiente obtuvo de la Casa Real una beca para continuar sus estudios en París, fue quien en noviembre de 1798 presentaba en nombre de su progenitor un memorial donde los canteros, habiendo cumplido ya con su contrata, exponían las pérdidas que esta les había ocasionado porque "además de la de ser nueva la cantera, mala su naturaleza por la situación de sierra fuerte, y de ningunos levantes, y crecidísimas las piezas que habían de sacarse, se agregan a estas la ingratitud de la piedra, tan resquebradiza y llena de pelos", de manera que los canteros tuvieron que sacar hasta ciento cuarenta piedras enteras para poder obtener las veinticinco que finalmente llegaron a Madrid, pues la mayor parte se estropeaban antes de acabar de prepararlas ${ }^{40}$. Los contratistas alegaron esto y más detalladas cir-

34 AGP, OP, leg. 286. Cargo y data, y copias de las cartas de pago y libramientos a los broncistas Leprince y Giardoni. Solo "buenas cuentas", pero no hay factura formal. Desde 22.10.1796 a 21.12.1798.

35 AGP, OP, leg. 196, mayo de 1798, pago a Juan Duque por pintura en el taller de los doradores franceses.

36 AGP, OP, leg. 441, Caja 1341/7. Fechos comunes de 1799. Esquela: "Obras de Palacio 22 de febrero de 1799. Expediente de D. Luis Le Prince, padre e hijo, doradores de cámara, sobre la concesión de la introducción de varias obras de bronce hechas en París. Se hallará en la Junta general de Comercio con el antecedente de 20 de noviembre de 1797 en que fueron nombrados por dichos doradores, y la anticipación de 30.000 rs. Igual esquela se ha puesto en f[ec] hos. de Casa Rl. y Obras de Palacio Nuevo".

37 Martín / Martínez Leiva, 2002.

38 Así, el gentilhombre de cámara Francisco del Castillo calificó de "escandalosa" e "inadmisible" la proposición que elevaron al rey para establecerse en España; cfr. Martín / Martínez Leiva, 2008: 483. Las noticias que estos autores dan sobre el capitel que a fines de la década querían cobrar los Leprince, y el dorado de los leones, han de encuadrarse en el contexto que estudiamos aquí, y al que ellos no hacen referencia.

39 AGP, OP, leg. 362. 1793-1795: Expediente sobre traída de dos trozos de columna de la Carolina, y de piezas de mármol de Luque.

40 AGP, OP, leg. 441, Caja 1341/13. Memorial de Domingo Álvarez y Manuel Galisteo, presentado el 14 de noviembre de 1798. "Señor. D. José Álvarez natural de la villa de Priego, y residente en esta corte, a nombre y poder de D. Domingo Álvarez y D. Manuel Galisteo, [...] hace presente haberse concluido por los referidos la saca de las pilastras del Valle de Luque, que se han de colocar en el Salón de Embajadores; en cuya manufactura no han podido menos de sacrificar parte notable de sus haciendas, por las graves dificultades que en ella se han experimentado, y que permanecían ocultas al tiempo de la contrata: pues [lo citado en el texto], que se ha considerado indispensable rozar alrededor cada una de las piezas, a pesar de las reflexiones que se han puesto, sin haberse verificado haya salido el menor pedazo sin esta fatiga; y como podrá textificar en forma, y en caso necesario D. Juan Bautista Galeoti, quien en esta disposición, y puestas en fila presenció hasta seis de ellas, en las dos veces que como comisionado pasó al reconocimiento de la obra: y aun esta fatiga no fuera de la mayor consideración, si a ella no se uniera la imponderable de haber experimentado peor suerte, y más grave detrimento de intereses en las 140 pilastras que se han sacado para conseguir el logro de poner en salvo las 25 presentadas; siendo digno de la atención de VM que la mayor parte de esta suma han padecido su ruina a la próxima ocasión de estar ya para conducirse: agregándose a estas pérdidas de grande momento la inutilidad del despojo; pues siendo este en otras canteras utilísimo para la empresa de sacar las piezas mayores, en esta se debe considerar como pilastras destrozadas, y a cuyo despojo prepondera el coste del trabajo: resultando a más de esto en perjuicio de los referidos sacadores por descuido del escribano que omitió insertar en la escritura de contrata el valor de las piezas de 4 pies abajo; el restante del 10 rs., en que sin inteligencia de los trabajadores tuvo a bien tasarlas a proporción el Sr. D. Juan de Villanueva; al del 12 en que se hallan tasados cada uno de los pies de las mayores a este tamaño". Piden "alguna ayuda de costa a su indemnización; como asimismo el que VM admita a su cargo las 


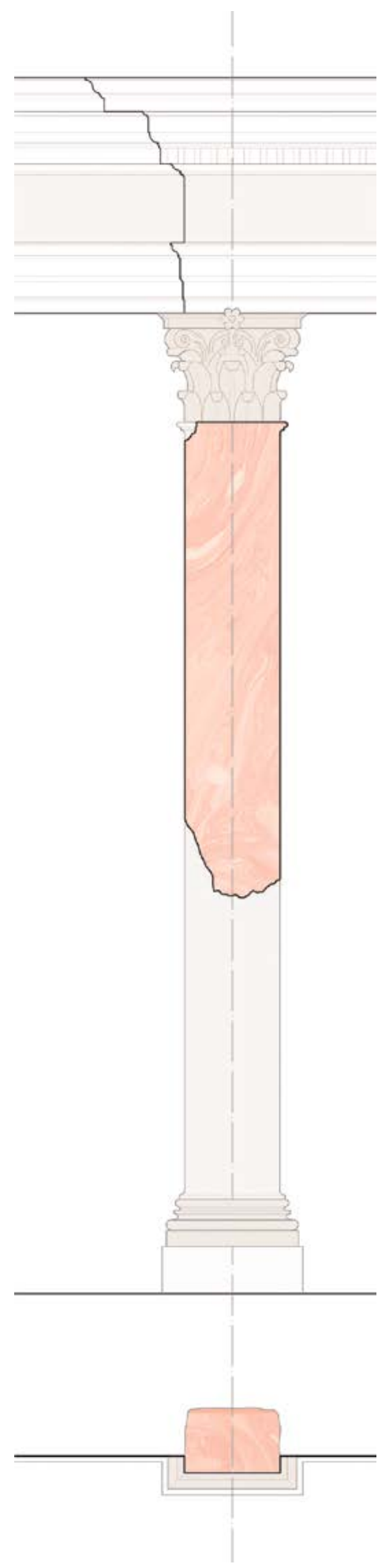

Fig. 4. Estudio de integración de uno de los fragmentos de fustes de mármol existentes en los almacenes de Palacio en el módulo arquitectónico básico del salón proyectado. cunstancias para obtener mayor compensación por su trabajo, pero Villanueva se atuvo a lo estipulado en el contrato ${ }^{41} ; \mathrm{y}$, en definitiva, solo consiguieron una gratificación compensatoria como reconocimiento de su buen cumplimiento ${ }^{42}$.

Las veinticinco piezas que Álvarez menciona, y que por tanto ya estaban en Madrid a finales de 1798, correspondían a las dos columnas y la totalidad de las pilastras. Su labra debió acometerse seguidamente en el taller de marmolistas dirigido por Juan Bautista Galeotti, y quedarían en los almacenes de la Obra de Palacio. Actualmente una decena de ellas, en su mayor parte fragmentadas, se conservan aún en los sótanos de la residencia regia, y corresponden con el fuste de nuestra reconstitución, bastando presentar una como ejemplo [fig. 4]. Su hermoso color rosa hubiera causado un magnífico efecto, pero desde luego la piedra es en exceso delicada; Sabatini y el rey atendieron más a la belleza y a la magnificencia que al sentido práctico cuando escogieron un mármol de cantera tan lejana, tan quebradizo, y en piezas monolíticas, para el Salón del Trono.

Nada más sabemos sobre traída de otros jaspes para este proyecto a partir de $1799 \mathrm{y}$, aunque cabe la posibilidad de que los marmolistas siguieran trabajando para ello en la Fábrica, porque la actividad de los talleres de Palacio generalmente está muy mal reflejada en la documentación, todo apunta a que tanto este tipo de obra como la de bronces quedaron detenidas entonces. Sin duda la muerte de Sabatini en 1797 había asestado un duro golpe al proyecto pues él, orgulloso de llevar a término un diseño suyo de tal importancia en el principal interior de Palacio, no hubiera cejado hasta llevarlo a término, mientras que su sucesor, Villanueva, ni podía sentirlo suyo, ni se interesó nunca mucho por ornatos internos, aunque fuesen de arquitectura.

Lástima, porque esta obra, que llegó a serlo puesto que se empezó y se invirtieron en ella grandes esfuerzos y gastos, superando el mero estado de proyecto, hubiera consti-

\footnotetext{
piezas restantes, que permanecen en la cantera por falta de operarios que las conduzcan, y como parece debe practicarse con arreglo al contexto de la escritura".

41 AGP, OP, leg. 441, Caja 1341/13. Fechado el 26 de noviembre de 1798 en El Escorial, considera que al habérseles recibido muchas piezas pequeñas a $10 \mathrm{rs}$./pie, "que no se incluían en su contrato", y "en no corto número, cuando estas deberían considerarse como desperdicios que tan sólo en un taller como el de Palacio pueden tener acomodo y empleo", solo procedía "aquella gratificación que sea de su R1. Agrado, en atención únicamente al buen cumplimiento de su contrata".

42 AGP, OP, leg. 441, Caja 1341/13. El 8 de enero de 1799 Juan de Villanueva responde a la orden del ministro de Hacienda Soler, comunicada el 29 de diciembre pasado, para que indicase "la ayuda de costa que se podrá conceder por vía de equidad" a los "canteros encargados en la saca de las pilastras de mármol que han de servir para el Salón de Embajadores; aunque no me es fácil conceptuar con exactitud cuáles pueden haber sido sus pérdidas", dice que 50 doblones para que queden "satisfechos de todos los perjuicios que alegan".
} 


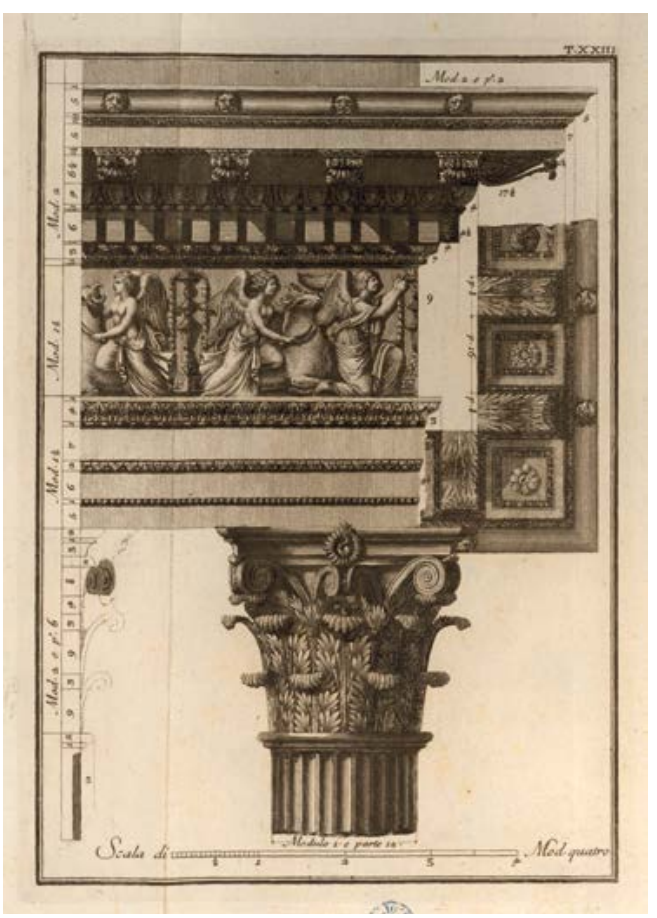

Fig. 5. Detalle de capitel y entablamento de orden corintio recogido en Il Vignola illustrato proposto da Giambattista Spampani e Carlo Antonini, Pagliarini, Roma 1770, tav. XXIII. BNE, ER/3176. tuido el más suntuoso interior civil del neoclasicismo en España. Precisamente por atenerse a las normas vitruvianas y gracias a la precisión de la memoria para la contrata de sus elementos de bronce, y a la abundancia de éstos, nos ha sido posible plantear una reconstitución gráfica muy exacta, cuya fundamentación conviene explicar para evidenciar que nada en ella es arbitrario. El dato esencial consiste en el empleo del orden corintio y en la precisa medida que Sabatini da de sus capiteles, "de alto dos pies y cinco dedos", recalcando además el rigor y ajuste la norma clásica: "y su ancho correspondiente de la orden corintia". Este dato respecto a la ortodoxia del orden, que por otro lado podríamos suponer evidente, permite deducir el módulo base que emplearía en todo el salón. Atendiendo a la descripción clásica de la Regola delli cinque ordini di architettura de Iacomo Barozzi di Vignola, infinitas veces reimpresa y que servía como canon académico ${ }^{43}$, vemos que establece el alto del capitel corintio en dos módulos y un tercio del mismo [fig. 5]. Por tanto, nuestro arquitecto ha traducido directamente esta regla a las medidas entonces usuales en España: el módulo equivale a un pie, y como esta medida castellana se fraccionaba en dedos, el ajuste más preciso a un tercio de pie es precisamente cinco dedos. Sabatini ha simplificado de la manera más fácil para sus colaboradores la definición en medidas de todo el proyecto. Con la proporción del orden encajan perfectamente las dimensiones de los fustes de mármol que se conservan en Palacio, pues su ancho se ajusta al de la pilastra, así como la parte labrada de sus costados, correspondiente a su resalte respecto del muro, mientras que el resto de la pieza quedaba embebida en la fábrica.

Definido el orden, su cornisa, la consiguiente articulación general de los muros, sin pedestal bajo las pilastras — dada la altura de estas y el nivel del arranque de la bóveda—, y el número de pilastras, cuyo número impar ya hemos explicado antes considerándolo consecuencia del uso de medias pilastras flanqueando las dos columnas, resulta necesario encajar el ritmo de los fustes. Para ello son determinantes, por supuesto, las posiciones de las puertas, pero también los adornos o grecas que Sabatini define entre ellas, unas de menor ancho (cinco pies y medio) y otras mayor (nueve pies) pero con idéntica altura (dos pies y medio). Esta alternancia nos da la pista del ritmo pareado de pilastras que, por otro lado, es el acuerdo necesario con las condiciones del muro sur en el que se intercalan vanos de balcón y paños ciegos de distinto ancho. Ese mismo ritmo alterno ya lo había aplicado Sabatini antes en el pavimento de este mismo Salón, que al parecer realizó por encargo de Carlos III pero que terminó ya bajo Carlos IV ${ }^{44}$.

43 Aunque de obra tan difundida no es necesario ofrecer más precisiones, hemos consultado el ejemplar de la edición de Roma de 1563, existente en BNE, ER 2501. Sabatini poseía una edición latina, pero también la titulada Il Vignola illustrato proposto da Giambattista Spampani e Carlo Antonini, Pagliarini, Roma 1770, del que hemos visto el ejemplar también en la BNE, ER 3176; cfr. Ruiz Hernando, 1993: 113.

${ }_{44}$ Noticias de mármoles para el Salón de embajadores, que por el contexto interpreto que estaban destinados a su pavimento, se encuentran en AGP, OP, leg. 364: el 13 de junio de 1788 Luis Bernasconi se refiere a la traída de jaspes de Espejón, San Agustín, Robledo de Chavela, Consuegra, Granada (verde de Lanjarón), Urda (negro) y de Cogolludo, colores que parecen concordar con el suelo existente ahora. En 1789 se trae, para el fajeado del dosel, mármol de Vi- 


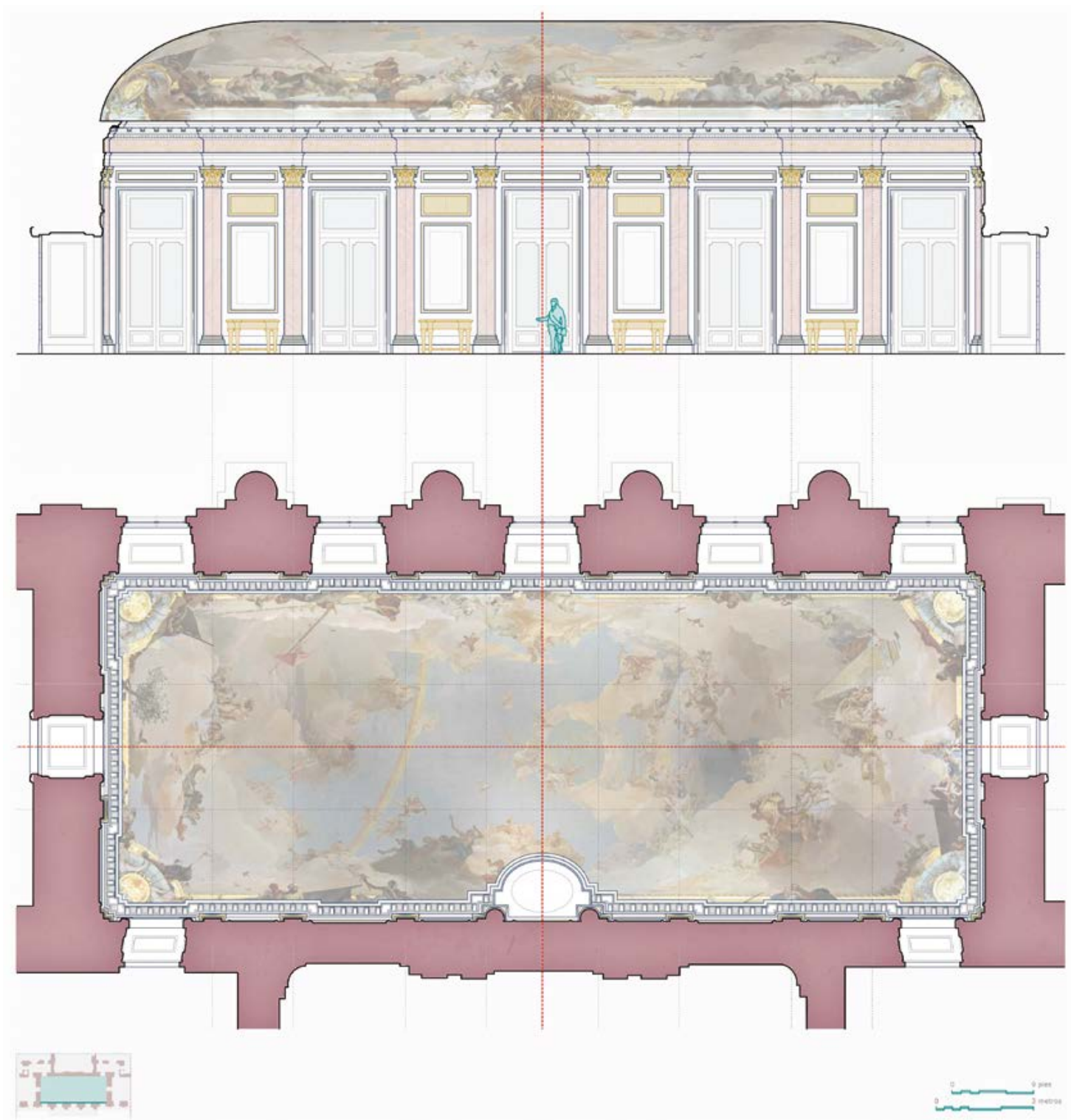

Fig. 6. Reconstitución gráfica del proyecto de Sabatini para el salón del trono. Plano de techos y alzado sur.

Puesto que la altura de las grecas, aun sin contar la moldura que recerca los recuadros en las que campean, es más alta que los capiteles, su única ubicación posible queda bajo el nivel de éstos, pero encima de los espejos, posición que se confirma también por la ausencia de estos elementos en los módulos de huecos de balcón [fig. 6]. La anchura de los seis espejos viene dada por la de las grecas en los recuadros sobre ellos; y su altura, por su perímetro total. Definido esto, y haciendo homogéneas las distancias entre los recuadros y las pilastras y cornisa, está determinada la dimensión del resto de los recuadros, pues debían quedar alineados como es evidente en una ordenación clásica.

llafamés, en Valencia, y quizá lo que se trae de Aspe entonces también era para este Salón; cfr. id., leg. 363. En los legajos de contabilidad de la Obra de Palacio correspondientes a estos años se encuentran pagos por la traída de mármol con destino al Salón de Embajadores, por ejemplo, en AGP OP 193 (C 550 a 551), del segundo semestre de 1795, y 194 (C 552-554) del primer semestre de 1795. 
Con toda esta restitución de los recuadros corresponde muy bien la medida total de la moldura de bronce empleada en el Salón, considerando que una parte de ella debía destinarse también a las jambas de las puertas ${ }^{45}$.

Por lo que a las puertas se refiere, Sabatini igualó las cuatro, eliminando la diferencia entre las del muro norte y las de las paredes cortas. Nos hemos atenido a estas, iguales a las que también utilizó en los demás salones, entre ellos el de besamanos y el del tocador de la reina (ver [figs. 1 y 2]). En estas dos salas que remodeló entre 1791 y 1794, el arquitecto decoró las sobrepuertas con unos elementos arquitectónicos que incluyen relieves, marcos ovalados - en el de besamanos-, molduras clasicistas aún con fuerte impronta tardobarroca y "clavos romanos". Para aproximarnos a una reconstitución hipotética de esas cuatro sobrepuertas iguales nos hemos valido de la longitud de la moldura que adornaba los óvalos de mármol, que forzosamente habían de ser horizontales, dada la cornisa. La medición de la moldura exterior, por otro lado, encaja con una guirnalda que adornase solo la mitad de los mismos [fig. 7]. Para cuanto rodea a esos relieves ovales es preciso partir de la analogía con las sobrepuertas en las dos citadas salas del cuarto de María Luisa, tan cercanas al Salón de besamanos del rey en todos los sentidos, cronológico, estilístico, y representativo. Tanto la dimensión de la cenefa, como la presencia de los clavos romanos, o de elementos equivalentes (cabezas de león en el Salón de besamanos de la reina) aproximan todos estos diseños del arquitecto.

La homologación de las cuatro puertas - puesto que sus sobrepuertas son iguales - y el ritmo de las pilastras obliga a pensar que Sabatini habría introducido un pequeño esviaje en los dos huecos del muro norte para acomodarlas a la pauta general de toda la composición. Las cenefas del friso de la cornisa se han ajustado a la longitud de la descripción asumiendo como hipótesis decorativa un doble festón en cada módulo dada la proporción del espacio que lo alberga. Igualmente sucede con las de los espejos.

Seguros como resultan los elementos arquitectónicos, el mobiliario es más aproximativo, pues carecemos, por ejemplo, de otros datos sobre las mesas aparte de su número y de algunos detalles sobre sus adornos. Por tanto hemos empleado una adaptación de las que el mismo arquitecto proyectó en 1791 para la inmediata Saleta, o sala de comer, de Carlos IV $^{46}$, con bronces del propio Domingo de Urquiza, pero hemos considerado probable que fuesen de dos tamaños diferentes: de las diez, seis tenían que estar bajo los espejos; es lógico que las otras cuatro se situaran entre los balcones, pero como esos entrepaños son más estrechos, también debían serlo las consolas, que proporcionalmente podían tener algo menos de profundidad. Para el escudo sobre el trono hemos seguido el modelo del bordado en el baldaquino que, por aquellos mismos años, y con parecida finalidad - para servir en los Reales Sitios- bordó López de Robredo. El solio, que sabemos habría estado rematado por una corona, cetro y espada, forzosamente contaba con un baldaquino sobre el cual carecemos de datos; puede que fuese sencillamente rectangular, pero por analogía estilística con piezas de la época hemos optado por una solución de base elíptica ${ }^{47}$. Las alusiones a los leones hacen pensar que la intención de Sabatini era reutilizar los mismos cuatro ya instalados por Carlos III, pero dorándolos de nuevo por los Leprince.

La magnificencia de este correcto salón neoclásico, en mármoles de color y bronces dorados, hubiera estado a la altura de lo más lujoso de las cortes europeas. De la frustración que puede producir su interrumpida realización nos consuela, sin embargo, que de este modo ha sobrevivido la suntuosa decoración de talla dorada y bordado, diseñada por Giambattista Natali y realizada en Nápoles para Carlos III ${ }^{48}$. No puede extrañar que su hijo la considerase pasada de moda,

45 Sobre los 1133 pies de moldura, a los recuadros de los muros corresponden 862 pies, y destinando la restante a las jambas de los huecos de paso (unos 275 pies), suman 1137 pies.

${ }^{46}$ Cfr. supra, nota 29.

${ }^{47}$ El proyecto de Dugourc para el Salón de besamanos de la reina, reproducido en Benito, 2009: 105, sigue este modelo, que el arquitecto francés también emplea en su proyecto de cama conservado en la Real Academia de Bellas Artes de San Fernando y reproducido en Sancho, 1991: 21.

48 Sancho, 2000. Ha sobrevivido íntegramente hasta la reciente sustitución, en 1993, del terciopelo original de su colgadura, que hubiera subsistido si el Palacio Real no tuviese otra función que la cultural. 


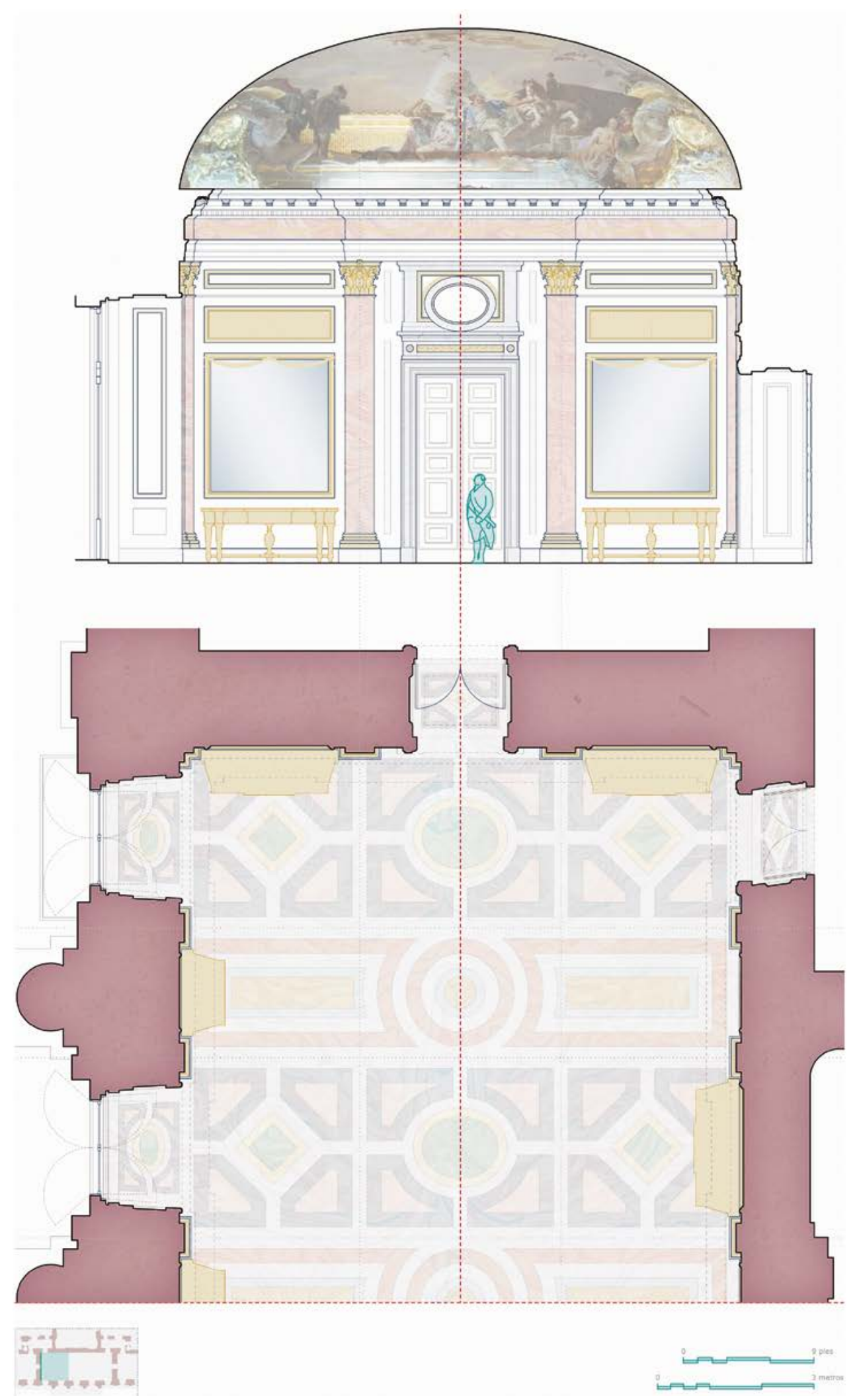

Fig. 7. Reconstitución gráfica del proyecto de Sabatini para el salón del trono. Planta y alzado oeste. 
como también reflejan los inventarios, donde el valor otorgado al mobiliario aún existente aquí no llega a la vigésima parte de los tres millones que hubieran costado solo los bronces de Carlos IV, en una operación suntuaria de gran impacto que hubiese impresionado a todos, aunque su diseño no hubiese sorprendido a ninguno, porque podía haber estado igual aquí que en San Petersburgo ${ }^{49}$. De haber recurrido a Dugourc el resultado hubiese sido, sin duda, más imaginativo, pero quizás lo que se requería para el Trono era, precisamente, un cosmopolitismo estable y convencional, ya en vísperas del 18 Brumario, cuando Napoleón se elevó a Primer cónsul.

\section{BIBLIOGRAFÍA}

Benito, Pilar (2009): “Fiebre de seda en los palacios de Carlos IV”. En: Jordán de Uríes, Javier/ Sancho, José Luis (eds.): Carlos IV, mecenas y coleccionista. Madrid: Patrimonio Nacional, pp. 93-118.

Benito, Pilar (2014): "El Salón del Trono del Palacio Real de Madrid”. En: Reales Sitios, 200, Madrid, pp. 50-67.

Fernández-Miranda y Lozana, Fernando [transcripción] (1988): Inventarios reales. Carlos III 1789-1790. Madrid: Patrimonio Nacional, t. I.

Gastinel-Coural, Chantal (1990): "Du nouveau sur les ornemanistes français de a fin du $18^{\mathrm{e}}$ siècle. À propos du palais d'Albe". En: L'objet d'art, 242, París, pp. 66-95.

Jordán de Urríes, Javier (2009): La Real Casa del Labrador. Madrid: Patrimonio Nacional.

Jordán de Urríes, Javier/ Sancho, José Luis (eds.) (2009): Carlos IV, mecenas y coleccionista. Madrid: Patrimonio Nacional. Junquera, Juan José (1979): La decoración y el mobiliario en los palacios de Carlos IV. Madrid: Sala editorial.

Martín, Fernando A./ Martínez Leiva, Gloria (2002): "Los Leprince: broncistas franceses al servicio de la Real Casa". En: Reales Sitios, 154, Madrid, pp. 64-75.

Martín, Fernando A./ Martínez Leiva, Gloria (2008): “Una obra de los Leprince en la Capilla Real de la Catedral de Sevilla”. En: Laboratorio de Arte, 21, Sevilla, pp. 481-490.

Ruiz Hernando, Antonio (1993): "La testamentaría de Francisco Sabatini”. En: Rodríguez, Delfín (ed.): Francisco Sabatini 1721-1797. La arquitectura como metáfora del poder. Madrid: Comunidad de Madrid/ Electa, pp. 91-114.

Sancho, José Luis (1988): “Saqueti y los salones del Palacio Real de Madrid”. En: Reales Sitios, 96, Madrid, pp. 37-44.

Sancho, José Luis (1991): "El piso principal del Palacio Real”. En: Reales Sitios, 109, Madrid, pp. 21-36.

Sancho, José Luis (1993): "Francisco Sabatini, primer arquitecto, director de la decoración interior en los palacios reales”. En: Rodríguez, Delfín (ed.): Francisco Sabatini 1721-1797. La arquitectura como metáfora del poder. Madrid: Comunidad de Madrid/ Electa, pp. 143-165

Sancho, José Luis (2000): “Una decoración napolitana para Carlos III, Rey de España: el Salón del Trono en el Palacio Real de Madrid". En: Antologia di Belle Arti. Studi sul Settecento II, 59-62, Roma, pp. 83-105.

Sancho, José Luis (2004): Palacio Real de Madrid. Madrid: Patrimonio Nacional.

Sancho, José Luis (2009): “'Tan perfectas como corresponde al gusto y grandeza de sus majestades'. Las artes en la corte de Carlos IV". En: Jordán de Urríes, Javier/ Sancho, José Luis (eds.): Carlos IV, mecenas y coleccionista. Madrid: Patrimonio Nacional, pp. 93-118.

Sancho, José Luis (2017): El Salón del Trono del Palacio Real de Madrid. Madrid: Patrimonio Nacional.

Fecha de recepción: 25-V-2020

Fecha de aceptación: 15-VII-2020

49 El Inventario de talla y dorado de la Testamentaría de Carlos III, publicado por Fernández-Miranda, 1988, tomo I: 199-200, tasa muy bajas — en ochocientos reales, más mil trescientos del dorado- estas consolas de Carlos III. El de la Testamentaría de Fernando VII estima todo el mobiliario del Salón en 130.000 reales: AGP, Registro 4807 , fol. $18 \mathrm{v}$. 